\title{
Pengukuran Kualitas Layanan Jd.Id Terhadap Minat Konsumen Dengan Metode TAM
}

\author{
Arief Rama Sena', Muhammad Ifan Rifani Ihsan' ${ }^{2}$ Dwiza Riana ${ }^{3}$ \\ 1,2,3 Ilmu Komputer, STMIK Nusa Mandiri \\ Indonesia \\ E-mail:1aarieframasena@gmail.com, ${ }^{2}$ ifanredirfani@gmail.com, 3 dwiza@nusamandiri.ac.id
}

\begin{abstract}
This study describes the user interest in the online JD.id buying and selling site using the TechologyAcceptence Model method or commonly called TAM. The variables used amounted to 3, namely, variable Ease of Use (Perceived Ease of Use), variable Use (Perceived Usefulness), variables Trust (Trust), and Variable Interest and User Behavior (Behavioral Intention to Use). The technique used in this study is multiple linear regression, in which multiple linear regression uses several tests that are useful to obtain the expected results from the questionnaire to be distributed to respondents, including testing validity, reliability testing, normality testing, multicollinearity testing, heteroscedasticity testing, and T testing to test the hypothesis described earlier. Multiple linear regression analysis was used to determine the effect of the dependent variable with the dependent variable. In this study, the data collection techniques carried out were the distribution of questions that must be answered by respondents, totaling 50 people who had visited the JD.id online sale and purchase site in the form of a questionnaire with a Likert scale, namely a questionnaire with 5 answer choices. The results showed that the independent variables, namely usefulness (Perceived Usefulness), usability (Perceived Ease of Use), and trust (Trust), had a significant influence on the dependent variable (dependent), namely interest in usage behavior (Behavioral Intention Variables to Use) with a value (r.Square) of $21.6 \%$
\end{abstract}

Keywords: TAM; JD.ID; Quantitative;

\begin{abstract}
Abstrak
Studi ini menggambarkan minat pengguna pada situs jual beli online JD.id menggunakan metode Techology Acceptence Model atau yang biasa disebut TAM. Variabel yang digunakan berjumlah 3 yaitu, variabel Kemudahan Penggunaan (Perceived Ease of Use), variabelKemanfaatan(Perceived Usefulness), variabel Kepercayaan (Trust), danVariabel Minat dan Perilaku Pengguna (Behavioral Intention to Use). Teknik yang digunakan dalam penelitian ini adalah regresi linier berganda, dimana dalam regresi linier berganda menggunakan beberapa pengujian yang berguna untuk memperoleh hasil yang diharapkan dari kuesioner yang akan disebarkan kepada responden, diantaranya adalah pengujian validitas, pengujian reliabilitas, pengujian normalitas, pengujian multikolinearitas, pengujian heteroskedastisitas, dan pengujian $\mathrm{T}$ untuk menguji hipotesis yang telah dijabarkan sebelumnya. Analisis regresi linier berganda digunakan untuk mengetahui pengaruh variabel dependen dengan variabel dependen.Dalam penelitian ini, teknik pengumpulan data yang dilakukan adalah penyebaran pertanyaan yang harus dijawab oleh responden yang berjumlah 50 orang yang pernah mengunjungi situs jual beli online JD.id berupa kuesioner dengan skala Likert yaitu kuesioner dengan 5 buah pilihan jawaban.Hasil penelitian menunjukan bahwa variabel tidak terikat (independent) yaitu
\end{abstract}


kemanfaatan (Perceived Usefulness), kegunaan (Perceived Ease of Use ), dan kepercayaan (Trust), memiliki pengaruh secara signifikan terhadap variabel terikat (dependent) yaitu minat perilaku penggunaan (Variabel Behavioral Intention to Use) dengan nilai ( $r$ Square) sebesar $21,6 \%$.

Kata Kunci: TAM; JD.ID; Kuantitatif.

\subsection{E-Commerce}

E-Commerce didefinisikan sebagai proses pembelian dan penjualan yang dilakukan melalui internet.[4]. Dengan penggunaan aplikasi e-commerce, hubungan antara perusahaan dengan pihak luar seperti distributor dan konsumen dapat dilakukan dengan lebih cepat, mudah lebih, dan lebih murah dibandinkan dengan menggunakan pendataan manajemen secara tradisional. Ecommerce adalah semua bentuk transaksi perdagangan barang atau jasa yang dilakukan secara elektronik [4]. Untuk memanfaatkan e-commerce memerlukan bantuan media berupa internet untuk menghubungkan dari komputer satu ke komputer lainnya untuk mengakses data yang memiliki jarak yang berjauhan.

\subsection{Internet}

Internet adalah jaringan komunikasi global yang terbuka dan menghubungkan ribuan jaringan komputer, melalui sambungan telepon umum maupun pribadi. [5]. internet menyimpan banyak macam jenis informasi, informasi yang baik dan informasi yang buruk, informasi yang benar maupun informasi yang salah. Semua informasi itu dapat dilihat menggunakan internet. Internet saat ini sudah banyak digunakan sehingga berkembang dengan pesat.

Saat ini masyarakat dapat dengan mudah menggunakan internet di warung internet ataupun menggunakan laptop dengan modem atau menggunakan wireless, bahkan dapat mengakses internet lewat telepon genggam. Dalam e-commerce, internet digunakan sebagai media pendukung untuk menggungkan e-commerce tersebut, melalui intenet proses e-commerce baru dapat dilakukan.

\subsection{Website}

Website merupakan suatu aplikasi berisikan dokumen multimedia teks, gambar, suara, animasi dan video di dalamnya dengan menggunakan protokol HTTP (hyper text transfer protocol). Untuk mengaksesnya diperlukan software yang dikenal dengan browser. Beberapa browser yang saat ini banyak dikenal di antaranya adalah: Internet Expoler yang dikembangkan oleh Microsoft, Google Chrome yang dikembangkan oleh Googlr, Mozila Firefox, Opera dan Safari yang dikembangkan oleh Apple. Saat ini telah banyak Websitee-commerce yang menyediakan layanan untuk pengguna agar dapat melakukan transaksi secara daring, 
salah satunya adalah JD.id yang merupakan obyek dari penelitian ini.

\subsection{TAM (Technology Acceptance Model)}

TAM adalah model yang banyak digunakan dalam penelitian TI karena model ini sederhana dan mudah diterapkan. TAM adalah adaptasi model TRA yang dikembangkan oleh Davis di tahun 1986. TAM digunakan untuk menjelaskan perilaku pengguna komputer. Model TAM menggunakan model TRA sebagai dasar untuk memastikan menspesifikasi hubungan kausal antar dua kunci kepercayaan diantaranya persepsi manfaat dan persepsi kemudahan penggunaan. TAM tidak hanya digunakan memperkirakan suatu penerimaan teknologi tetapi juga memaparkan secara jelas tentang penerimaan suatu teknologi, dengan hasilnya para peneliti dan para praktisi mampu mengidentifikasi faktor apa saja yang tidak diterimaserta memberikan kemungkinan langkah yang benar. Model TAM dibuat dengan tujuan untuk memberikan dasar langkah dari efek faktor luar terhadap kepercayaan internal, sikap, dan niat. TAM diadopsi dari model TRA, yaitu teori tindakan beralasan yang dikembangkan oleh Fishbein dan Ajzen [6].

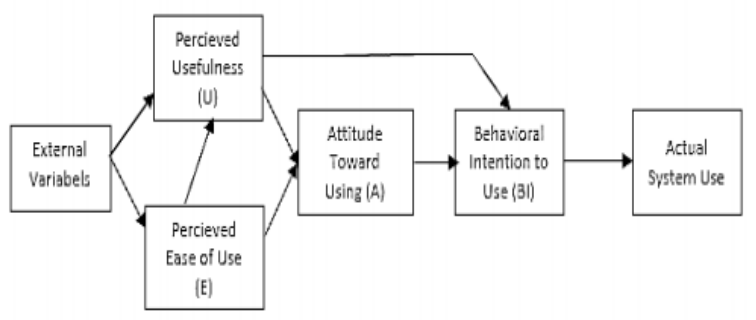

Sumber: [6]

Gambar II.1. Technology Acceptance Model

TAM dikembangkan lebih lanjut oleh Davis. Pengembangan ini bertujuan untuk mengetahui penerimaan pengguna teknologi komputer dimana penggunaan teknologi komputer ditentukan dari tiga variabel yaitu: minat perilaku, variabel minat perilaku dipengaruhi oleh dua variabel lainnya yaitu: sikap terhadap perilaku dan persepsi kegunaan. Variabel Persepsi terhadap kegunaan serta variabel persepsi terhadap kemudahan penggunaan teknologi menmpengaruhi variabel sikap individu terhadap penggunaan teknologi, lalu ditenukan apakah pengguna berminat menggunakan teknologi yang diteliti.

\subsection{Uji Validitas dan Reliabilitas}

Analisis validitas dan reliabilitas dilakukan untuk menunjukkan sejauh mana suatu alat pengukur itu mengukur apa yang diukur dan menunjukkan sejauh mana suatu alat pengukur dapat dipercaya atau dapat diandalkan. Apabila data sudah valid dan reliable, maka penelitian dapat dilanjutkan [7]. 


\subsection{Uji Asumsi Klasik}

Uji asumsi klasik adalah persyaratan statistik yang harus dipenuhi pada anatisis regresi linier berganda agar data yang dihasilkan dapat bermanfaat. Uji asumsi klasik ini ada beberapa bagian, yaitu uji normalitas data, uji multikolinearitas, uji autokorelasi, dan uji heteroskedastisitas [7].

\section{a. Uji Normalitas}

Uji Normalitas dilakukan untuk melihat bahwa suatu data terdistribusi secara normal atau tidak. Normalitas data dipenuhi jika nilai statistik Kolmogrof-Smirnov dengan tingkat signifikansi $<0.05$ diartikan distribusi data tidak normal, tingkat signifikansi $>0.05$ diartikan distribusi data normal [8].

\section{b. Uji Multikolinearitas}

Uji Multikolinearitas dilakukan untuk mengetahui apakah terdapat korelasi antar variabel bebas. Apabila terdapat korelasi, maka terjadi masalah Multikolinearitas. Seharusnya tidak terjadi korelasi diantara variabel independen, dalam model regresi yang baik [8].

\section{c. Uji Autokrelasi}

Uji Autokorelasi bertujuan untuk menguji apakah model regresi linier ada korelasi antara kesalahan penggangu pada periode $\mathrm{t}$ dengan kesalahan pengganggu pada periode t- 1 (sebelumnya) [9].

\section{d. Uji Heteroskedastisitas}

Uji Heteroskedastisitas ini untuk mengetaui dan menguji apakah dalam model regresi terjadi ketidaksamaan variabel dari residual atau sisa satu pengamatan ke pengamatan yang lain, namun variabel lain dianggap tetap, jika hasil menyatakan sama maka disebut homoskedastisitas dan jika berbeda disebut heterokedastisitas [10].

\subsection{Uji T}

Uji $\mathrm{T}$ adalah alat uji yang digunakan untuk mencari ada tidaknya perbedaan antara dua means dari dua sample/kelompok data dengan menggunakan nilai yang ditetapkan yaitu nilai kritis (t-tabel) ditentukan bedasarkan tingkat signifikan $(\alpha)$ dan derajat kebebasan $(\mathrm{df}=\mathrm{n}-\mathrm{k}-1)$ yang ditetapkan yaitu $\alpha=5 \%$ atau 0,05 dengan kriteria pengujian bahwa 1 [10].

\subsection{Regresi Linear Berganda}

Regresi Linier Berganda adalah regresi yang memiliki satu variabel dependent (tidak bebas) dan lebih dari satu variabel independent (bebas). Analisis ini untuk mengetahui arah hubungan antara variabel, apakah masing masing variabel independen berhubungan positif atau negatif dan untuk memprediksi nilai dari variabel independen mengalami kenaikan atau penurunan [11].

Data yang digunakan biasanya berskala interval atau rasio. Untuk 
meramalkan Y, apabila semua nilai variabel bebas diketahui, dipergunakan persamaan regresi linier berganda. Model persamaan regresi linier berganda adalah sebagai berikut:

$$
y=a+b_{1} x_{1}+b_{2} x_{2}+\cdots+b_{n} x_{n}(1)
$$

Keterangan:

$y=$ Variabel terikat dependen (nilai yang diprediksikan)

$x_{1}$ dan $x_{2}=$ Variabel independen

$a=$ Konstanta $y$ (Nilai apabila $x_{1}, x_{2} \ldots \ldots x_{n}$ $=0$ )

$b_{1}, b_{2}=$ Koefisien Regresi (nilai peningkatan atau penurunan)

\section{Metode Penelitian}

Penelitian ini dilakukan dengan metode penelitian kuantitatif. Pada penelitian ini menggunakan 3 variabel tidak terikat, yaitu: persepsi kemudahan penggunaan (perceived ease of use), persepsi manfaat (perceived usefulness), kepercayaan (trust) dan satu variabel terikat, yaitu: minat perilaku penggunaan (behavioral intention to use). Penelitian ini diawali dari pengumpulan data berupa kuesioner yang diisi responden kemudian dilakukan uji validitas dan uji reliabilitas.

Lalu setelah kuesioner dianggap valid dan reliabel, pengumpulan data dilakukan kembali. Dalam penelitian ini dilakukan uji asumsi klasik. Uji asumsi klasik merupakan persyaratan statistik yang wwjib dipenuhi pada analisis regresi linear berganda yang berbasis ordinary least square (OLS) [12]. Langkah pengujian dimulai dengan uji normalitas, uji multikolinearitas dan uji heterokedastisitas. Hasilnya kemudian di lakukan analisis data untuk menguji pengaruh kedua variabel penentu penerimaan teknologi dengan menggunakan Regresi Linear Berganda dan dilanjutkan dengan analisis-analisis, yaitu:

a. Uji F, merupakan uji koefisien regresi secara bersama-sama untuk menguji signifikansi pengaruh beberapa variabel tidak terikat terhadap terikat.

b. Koefisien determinasi, untuk mengukur seberapa jauh kemampuan model dalam menerangkan variasi variabel terikat.

\section{HASIL DAN PEMBAHASAN}

\subsection{Uji Validitas}

Jika ${ }_{\text {rhitung }}>$ rtabel, maka pernyataan tersebut dapat dinyatakan valid. Hasil pengujian validitas untuk setiap variabel ditampilkan pada tabel berikut :

a. Persepsi Kemudahan Penggunaan

\section{(Perceived Ease Of Use)}

Terdapat empat pernyataan yang ditunjukan oleh Corrected Item-Total Correlation atau (rhitung). Pada tabel IV.1 seluruh skor Corrected Item-Total Correlation (rhitung) menunjukan lebih besar dari rtabel sebesar 0,273. Hal ini menunjukan bahwa setiap pernyataan yang diukur pada variabel kemanfaatan persepsian adalah valid. 
Tabel IV.3. Hasil Uji Validitas Persepsi

Tabel IV.1. Hasil Uji Validitas Persepsi

Kemudahan Penggunaan

\begin{tabular}{|c|c|c|c|}
\hline No & ${ }_{\mathrm{r}}$ Hitung & ${ }_{\mathrm{r}}$ Tabel & Keterangan \\
\hline 1. & 0,663 & 0,273 & Valid \\
\hline 2. & 0,695 & 0,273 & Valid \\
\hline 3. & 0,859 & 0,273 & Valid \\
\hline 4. & 0,734 & 0,273 & Valid \\
\hline
\end{tabular}

b. Persepsi Manfaat (Perceived Usefulness)

Terdapat tiga pernyataan yang ditunjukan oleh Corrected Item-Total Correlation atau (rhitung). Pada tabel IV.2, seluruh skor Corrected Item-Total Correlation (rhitung) menunjukan lebih besar dari rtabel sebesar 0,273. Hal ini menunjukan bahwa setiap pernyataan yang diukur pada variabel persepsi manfaat adalah valid.

Tabel IV.2. Hasil Uji Validitas Persepsi

Manfaat

\begin{tabular}{|c|c|c|c|}
\hline No & rHitung & rTabel & Keterangan \\
\hline 1. & 0,731 & 0,273 & Valid \\
\hline 2. & 0,689 & 0,273 & Valid \\
\hline 3. & 0,864 & 0,273 & Valid \\
\hline
\end{tabular}

c. Kepercayaan (Trust)

Terdapat tiga pernyataan yang ditunjukan oleh Corrected Item-Total Correlation atau (rhitung). Pada tabel IV.3 seluruh skor Corrected Item-Total Correlation (rhitung) menunjukan lebih besar dari rtabel sebesar 0,273. Hal ini menunjukan bahwa setiap pernyataan yang diukur pada variabel kepercayaan adalah valid.
Kepercayaan

\begin{tabular}{|c|c|c|c|}
\hline No & ${ }_{\mathrm{r}}$ Hitung & ${ }_{\mathrm{r}}$ Tabel & Keterangan \\
\hline 1. & 0,799 & 0,273 & Valid \\
\hline 2. & 0,840 & 0,273 & Valid \\
\hline 3. & 0,416 & 0,273 & Valid \\
\hline
\end{tabular}

d. Minat Perilaku Penggunaan (Behavioral Intention To Use)

Terdapat tiga pernyataan yang ditunjukan oleh Corrected Item-Total Correlation atau (rhitung). Pada tabel IV.4 seluruh skor Corrected Item-Total Correlation (rhitung) menunjukan lebih besar dari rtabel sebesar 0,273. Hal ini menunjukan bahwa setiap pernyataan yang diukur pada variabel kepercayaan adalah valid.

Tabel IV.4. Hasil Uji Validitas Minat

Perilaku Penggunaan

\begin{tabular}{|c|c|c|c|}
\hline No & ${ }_{\mathrm{r}}$ Hitung & ${ }_{\mathrm{r}}$ Tabel & Keterangan \\
\hline 1. & 0,867 & 0,273 & Valid \\
\hline 2. & 0,880 & 0,273 & Valid \\
\hline 3. & 0,896 & 0,273 & Valid \\
\hline
\end{tabular}

\subsection{Uji Realibilitas}

Uji reliabilitas dari setiap variabel yang digunakan dalam penelitian ini menggunakan metode Cronbach's Alpha. Pengujian instrumen dinyatakan reliabel jika nilai

Tabel IV.5. Hasil Uji Reabilitas

\begin{tabular}{|c|c|c|c|}
\hline Variabel & $\begin{array}{c}\text { Cronbach's } \\
\text { Alpha }\end{array}$ & $\begin{array}{c}\text { Cronbach's } \\
\text { Alpha yang } \\
\text { diisyaratkan }\end{array}$ & Keterangan \\
\hline Kegunaan & 0,636 & $>0,273$ & reliabel \\
\hline Manfaat & 0,714 & $>0,273$ & reliabel \\
\hline
\end{tabular}
koefisien reliabilitas $>0,60$. 


\begin{tabular}{|c|c|c|c|}
\hline Kepercayaan & 0,507 & $>0,273$ & reliabel \\
\hline $\begin{array}{c}\text { Minat } \\
\text { Perilaku } \\
\text { Penggunaan }\end{array}$ & 0,852 & $>0,273$ & reliabel \\
\hline
\end{tabular}

Berdasarkan tabel 5 diketahui bahwa variabel kegunaan, manfaat, kepercayaan, dan minat perilaku penggunaan memiliki Cronbach's Alpha lebih besar dari 0,273 yang artinya data reliabel.

\subsection{Uji Asumsi Klasik}

a. Hasil Uji Normalitas

Statistik uji yang digunakan adalah OneSample Kolmogrov Smirnov Test didasarkan pada nilai Asymp.Sig. (2-tailed) dengan ketentuan jika Asymp. Sig.(2-tailed) > alpha yang ditetapkan sebelumnya sebesar $(0,05)$ maka data berdistribusi normal dan sebaliknya jika < alpha yang ditentukan, maka data tidak berdistribusi normal.

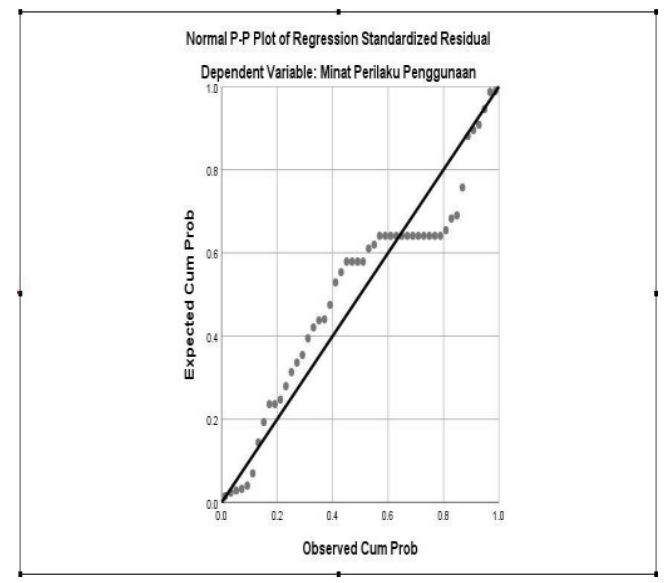

Gambar IV.1. Hasil Uji Normalitas

Pada gambar IV.1 di atas, terlihat bahwa titik-titik yang ada selalu mengikuti dan mendekati garis diagonalnya. Maka, dapat disimpulkan bahwa nilai residual berdistribusi normal sehingga syarat normalias nilai residual untuk analisis regresi dapat terpenuhi.

\section{b. Hasil Uji Multikolinearitas}

Uji multikolinearitas berfungsi sebagau penguji model regresi menemukan adanya korelasi antar variabel bebas. Model regresi yang baik seharusnya tidak terjadi multikolinearitas, jika VIF lebih kecil dari 10 dan mempunyai angka tolerance lebih besar dari 0,10 .

Tabel IV.6. Hasil Uji Uji Multikolinearitas

\begin{tabular}{|c|c|c|}
\hline \multirow{2}{*}{ Model } & \multicolumn{2}{|c|}{ Collinearity Statistics } \\
\cline { 2 - 3 } & Tolerance & VIF \\
\hline $\begin{array}{c}\text { Persepsi } \\
\text { Kemanfaatan }\end{array}$ & 0,961 & 1.040 \\
\hline $\begin{array}{c}\text { Persepsi } \\
\text { Kegunaan }\end{array}$ & 0,867 & 1.154 \\
\hline $\begin{array}{c}\text { Persepsi } \\
\text { Kepercayaan }\end{array}$ & 0,898 & 1.113 \\
\hline
\end{tabular}

Berdasarkan Tabel IV.6 menunjukan variabel kemanfaatan memiliki nilai tolerance sebesar 0,961 dan nilai VIF 1,040. Variabel kegunaan memiliki nilai tolerance 0,867 dan nilai VIF 1,154. Variabel kepercayaan memiliki nilai tolerance 0,896 dan nilai VIF 1,113 Berdasarkan hasil uji multikolinearitas pada tabel tersebut, maka seluruh variabel tidak terikat pada model regresi memiliki nilai tolerance $\geq 0,10$ dan nilai $\mathrm{VIF} \leq 10$. Hal ini memenuhi asumsi bahwa tidak terjadi multikolinearitas. 
c. Hasil Uji Heteroskedastisitas

Untuk

mendeteksi

adanya

heteroskedastisitas dalam penelitian ini, digunakan grafik scatterplot antara nilai variabel terikat (ZPRED) dengan residualnya (SRESID).

\begin{tabular}{|c|c|c|c|c|c|c|c|c|}
\hline \multicolumn{9}{|c|}{ Coefficients $^{a}$} \\
\hline & & \multicolumn{2}{|c|}{ Unstandardized Coefficients } & \multirow{2}{*}{$\begin{array}{c}\text { Standardized } \\
\text { Coefficients } \\
\text { Beta }\end{array}$} & \multirow[b]{2}{*}{$t$} & \multirow[b]{2}{*}{ Sig. } & \multicolumn{2}{|c|}{ Collinearity Statistics } \\
\hline \multicolumn{2}{|c|}{ Model } & $B$ & Std. Error & & & & Tolerance & VIF \\
\hline \multirow[t]{4}{*}{1} & (Constant) & 4.700 & 1.954 & & 2.406 & .020 & & \\
\hline & Persepsi Kemanfaatan & .066 & .093 & .100 & .705 & .485 & .961 & 1.040 \\
\hline & Persepsi Kegunaan & .009 & .095 & .014 & .094 & .926 & .867 & 1.154 \\
\hline & Persepsi Kepercayaan & .235 & .115 & .300 & -2.036 & .048 & .898 & 1.114 \\
\hline
\end{tabular}

\section{Gambar IV.2. Hasil Uji Heteroskedastisitas}

Pada gambar di atas diketahui bahwa nilai signifikasi variabel persepsi kemanfaatan sebesar 0,485 lebih besar dari 0,05 , artinya tidak terjadi heteroskedastisitas pada kemanfaatan. Sementara itu, diketahui nilai signifikasi variabel kegunaan yakni 0,926 lebih besar dari 0,05 , antinya tidak terjadi heteroskedastisitas pada variabel $p$ dan diketahui nilai signifikasi variabel kepercayaan yakni 0,048 lebih kecil dari 0,05 .

\section{d. Hasil Uji Regresi Linear Berganda}

Bentuk model prediksi yang telah diperoleh dengan metode regresi linear berganda menghasilkan nilai pada gambar IV.3.

H1: Variabel kemanfaatan berpengaruh signifikan pada variabel minat perilaku penggunaan.
H2: Variabel kegunaan berpengaruh signifikan pada variabel minat perilaku penggunaan.

H3: Variabel kepercayaan berpengaruh signifikan pada variabel minat perilaku penggunaan.

\begin{tabular}{|c|c|c|c|c|c|c|c|c|}
\hline \multicolumn{9}{|c|}{ Coefficients $^{\mathrm{a}}$} \\
\hline & & \multicolumn{2}{|c|}{ Unstandardized Coefficients } & \multirow{2}{*}{$\begin{array}{l}\text { Standardized } \\
\text { Coefficientis } \\
\text { Beta }\end{array}$} & \multirow[b]{2}{*}{ t } & \multirow[b]{2}{*}{ Sig. } & \multicolumn{2}{|c|}{ Collinearity Statistics } \\
\hline \multicolumn{2}{|c|}{ Model } & B & Stod. Error & & & & Tolerance & VIF \\
\hline \multirow[t]{4}{*}{1} & (Constant) & 7.319 & 3.098 & & 2.363 & .022 & & \\
\hline & Persepsi Kemanfaatan & .106 & .148 & .092 & .715 & .478 & .961 & 1.040 \\
\hline & Persepsi Kegunaan & .803 & .151 & .544 & 4.000 & .000 & .867 & 1.154 \\
\hline & Persepssi Kepercayaan & -1115 & .183 & -.084 & -629 & .532 & .898 & 1.114 \\
\hline
\end{tabular}

Gambar IV.3. Hasil Uji Regresi Linear Berganda (Coefficient)

Dari gambar diatas menunjukkan bahwa nilai Sig untuk variabel kemanfaatan sebesar $0,478>0,05$ maka hipotesis ditolak, artinya variabel kemanfaatan tidak berpengaruh signifikan pada variabel minat perilaku penggunaan. Lalu untuk variabel kegunaan sebesar $0,000<0,05$ maka hipotesis diterima, artinya variabel kegunaan berpengaruh signifikan pada variabel minat perilaku penggunaan. Kemudian untuk variabel kepercayaan sebesar 0,532>0,05 maka hipotesis ditolak, artinya variabel kepercayaan tidak berpengaruh signifikan pada variabel minat perilaku penggunaan. 


\begin{tabular}{|c|c|c|c|c|c|c|}
\hline \multicolumn{7}{|c|}{ ANOVA $^{a}$} \\
\hline \multicolumn{2}{|c|}{ Model } & $\begin{array}{l}\text { Sum of } \\
\text { Squares }\end{array}$ & df & Mean Square & $\mathrm{F}$ & Sig. \\
\hline \multirow[t]{3}{*}{1} & Regression & 33.357 & 3 & 11.119 & 5.491 & $.003^{b}$ \\
\hline & Residual & 93.143 & 46 & 2.025 & & \\
\hline & Total & 126.500 & 49 & & & \\
\hline
\end{tabular}

Gambar IV.4. Hasil Uji Regresi Linear Berganda (ANOVA)

H4: Variabel kemanfaatan, kegunaan, dan kepercayaan berpengaruh signifikan secara bersama-sama terhadap variabel minat perilaku penggunaan.

Berdasarkan data diatas nilai Sig sebesar $0,003<0,005$, maka dapat disimpulkan bahwa hipotesis diterima, artinya ketiga variabel tidak terikat berpengruh signifikan secara bersama-sama terhadap variabel terikat.

\section{e. Hasil Uji T}

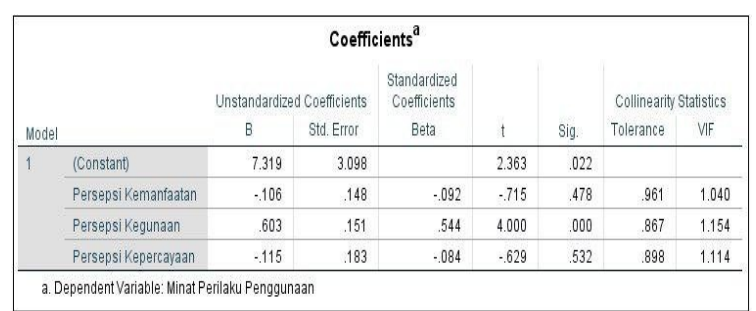

Gambar IV.5. Hasil Uji T

Berdasarkan hasil uji di atas, nilai variabel kemanfaatan adalah $-0,715<2,009$ maka dapat disimpulkan bahwa tidak terdapat pengaruh signifikan antara variabel kemanfaan terhadapat vairabel minat perilaku penggunaan, nilai variabel kegunaan adalah 4,00 > 2,009 maka dapat disimpulkan bahwa terdapat pengaruh signifikan antara variabel kegunaan terhadapat variabel minat perilaku penggunaan, dan nilai variabel kepercayaan adalah -0,084 2,009 maka dapat disimpulkan bahwa tidak terdapat pengaruh signifikan antara variabel kepercayaan terhadapat vairabel minat perilaku penggunaan.

\section{f. Hasil Uji Determinasi}

\begin{tabular}{|c|c|c|c|c|}
\hline \multicolumn{5}{|c|}{ Model Summary } \\
\hline Model & $\mathrm{R}$ & R Square & $\begin{array}{l}\text { Adjusted R } \\
\text { Square }\end{array}$ & $\begin{array}{l}\text { Std. Error of } \\
\text { the Estimate }\end{array}$ \\
\hline 1 & $.514^{\mathrm{a}}$ & .264 & .216 & 1.423 \\
\hline
\end{tabular}

Gambar IV.6. Hasil Uji Determinasi

Berdasarkan hasil uji diatas bahwa, besarnya pengaruh ketiga variabel tidak terikat terhadap variabel terikat adalah 0,216 atau $21,6 \%$, sedangkan sisanya $78,4 \%$ dipengaruhi oleh variabel lain diluar penelitian.

\section{KESIMPULAN}

Berdasarkan pembahasan seperti yang telah diuraikan dapat ditarik kesimpulan bahwa: Pada uji $\mathrm{T}$ membuktikan bahwa variabel kemanfataan memiliki pengaruh signifikan terhadap variabel minat perlaku penggunaan, sementara variabel kepercayaan tidak memiliki pengaruh yang signifikan terhadap variabel minal perilaku penggunaan.

Variabel tidak terikat dalam penelitian ini menerangkan sebesar 0,216 atau sebesar $21,6 \%$ mengenai minat penggunaan website 
JD.id. Sedangkan sisanya 78,4\% dijelaskan oleh variabel lain yang tidak dimasukan dalam penelitian ini.

\section{DAFTAR PUSTAKA}

[1] A. R. M. Kanter, M. Bakri, and I. Koeswahyono, "Keabsahan jual beli atas objek jaminan hak tanggungan oleh bank yang dilakukan tanpa melalui mekanisme lelang," Perspekt. Hukum2, vol. 17, 2017.

[2] D. W. Suci, K. Raharjo, and R. Andini, "EFFECT OF PUBLIC PERCEPTION OF INTEREST USING INTERNET BANKING SERVICE (STUDY IN PT. BANK UOB INDONESIA, SEMARANG)," J. Account., pp. 1-12, 2017.

[3] M. R. Abdullah and R. I. Patintingan, "TINJAUAN EKONOMI SYARIAH TERHADAP SISTEM JUAL BELI KOPI SECARA TENDER (STUDI KASUS KECAMATAN

\section{LATIMOJONG KABUPATEN}

LUWU)," J. Islam. Econ. Law, vol. 3, no. 2, pp. 70-84, 2018.

[4] J. B. Karay, I. Sembiring, and H. D. Purnomo, "PEMETAAN BERBAGAI PERMASALAHAN DALAM SECURITY E-COMMERCE," Pros. Semin. Nas. GEOTIK 2017, pp. 146156, 2017.

[5] A. Gafar, "Penggunaan Internet Sebagai
Media Baru dalam Pembelajaran,” Pengguna. Internet Sebagai Media Baru dalam Pembelajaran, vol. 8, no. 2, pp. 36-43, 2008.

[6] T. W. Maharidho, A. T. Haryono, and E. H. Wahyono, "PENGARUH TECHNOLOGY MODEL (TAM) TERHADAP CORPORATE CREDIBILTY DAN BEHAVIORAL INTENTION PADA APLIKASI STREAMING MUSIK SPOTIFY (Studi kasus pada pengguna Spotify di Semarang)," J. Manage., vol. 4, 2018.

[7] A. M. Putri, T. Amelia, and R. Santoso, "POLA PENERIMAAN MAHASISWA TERHADAP PRESENSI RFID STIKOM SURABAYA MENGGUNAKAN UTAUT 2," Jsika, vol. 6, no. 3, pp. 1-7, 2016.

[8] J. R. Assa, L. Kalangi, and W. Pontoh, "PENGARUH

PEMERIKSAAN PAJAK DAN SANKSI PERPAJAKAN TERHADAP KEPATUHAN WAJIB PAJAK PADA KANTOR PELAYANAN PAJAK PRATAMA MANADO," J. Ris. Akunt. Going Concern, vol. 13, no. 4, pp. 516-522, 2018.

[9] J. A. Juara et al., "PENGARUH TOTAL ASSETS TURNOVER(TATO), NET PROFIT MARGIN(NPM) DAN DEBT TO EQUITY

RATIO(DER) 
TERHADAP PERUBAHAN LABA DI PT. PERKEBUNAN NUSANTARA III (PERSERO) MEDAN TAHUN 20122017," J. AKRAB JUARA, vol. 4, no. 2, pp. 67-76, 2019.

[10]A. Kurniawan, K. P. Utomo, and I. Emita, "Penerapan Motivasi Kerja Sebagai Ciri Kualitas Pegawai Untuk Mendorong Kepuasan Masyarakat Pada Kantor Pelayanan Kecamatan Bekasi Utara," J. Adm. dan Kesekretarisan, vol. 3, no. September, pp. 95-105, 2018.

[11] T. Syahputra, J. Halim, and K. Peranginangin, "Penerapan Data Mining Dalam
Memprediksi Tingkat Kelulusan Uji

Kompetensi (UKOM) Bidan Pada STIKes Senior Medan Dengan Menggunakan Metode Regresi Linier Berganda," J. Sains dan Komput., vol. 17, no. 1, pp. 1-07, 2018.

[12] M. D. Atuti, A. T. Haryono, and M. M. Warso, “ANALISIS PENGARUH REKRUITMEN KEMAMPUAN, KEPRIBADIAN, MOTIVASI, KOMITMEN TERHADAP KINERJA SDM PADA PT BINA JASA SUMBER SARANA,” J. Manaj., pp. 1-7, 2017. 